\title{
Highly frequent promoter methylation and PIK3CA amplification in non-small cell lung cancer (NSCLC)
}

Meiju $\mathrm{Ji}^{1+}$, Haixia Guan ${ }^{2 \dagger}$, Cuixia Gao ${ }^{1}$, Bingyin Shi ${ }^{1}$ and Peng Hou ${ }^{1 *}$

\begin{abstract}
Background: Lung cancer is the leading cause of cancer-related death worldwide. Genetic and epigenetic alterations have been identified frequently in lung cancer, such as promoter methylation, gene mutations and genomic amplification. However, the interaction between genetic and epigenetic events and their significance in lung tumorigenesis remains poorly understood.

Methods: We determined the promoter methylation of 6 genes and PIK3CA amplification using quantitative methylation-specific PCR (Q-MSP) and real-time quantitative PCR, respectively, and explore the association of promoter methylation with PIK3CA amplification in a large cohort of clinically well-characterized non-small cell lung cancer (NSCLC).

Results: Highly frequent promoter methylation was observed in NSCLC. With 100\% diagnostic specificity, excellent sensitivity, ranging from 45.8 to $84.1 \%$, was found for each of the 6 genes. The promoter methylation was associated with histologic type. Methylation of CALCA, CDH1, DAPK1, and EVX2 was more common in squamous cell carcinomas (SCC) compared to adenocarcinomas (ADC). Conversely, there was a trend toward a higher frequency of RASSFIA methylation in ADC than SCC. In addition, PIK3CA amplification was frequently found in NSCLC, and was associated with certain clinicopathologic features, such as smoking history, histologic type and pleural indentation. Importantly, aberrant promoter methylation of certain genes was significantly associated with PIK3CA amplification.
\end{abstract}

Conclusions: Our data showed highly frequent promoter methylation and PIK3CA amplification in Chinese NSCLC population, and first demonstrated the associations of gene methylation with PIK3CA amplification, suggesting that these epigenetic events may be a consequence of overactivation of PI3K/Akt pathway.

Keywords: Promoter methylation PI3K/Akt pathway, PIK3CA amplification, non-small cell lung cancer (NSCLC), clinicopathologic characteristics

\section{Background}

Lung cancer is the number one cancer killer in China and soon will reach epidemic levels worldwide [1]. Epidemiological evidence has documented that approximately 41.8 men and 19.3 women per 100,000 Chinese individuals died of lung cancer in 2005 [2]. This disease is largely associated with smoking. While in developed

\footnotetext{
* Correspondence: phou@mail.xjtu.edu.cn

+ Contributed equally

'Department of Endocrinology, The First Affiliated Hospital of Xi'an Jiaotong University College of Medicine, Xi'an 710061, the People's Republic of China Full list of author information is available at the end of the article
}

countries smoking rates are decreasing, the use of tobacco products is increasing in the developing countries. In combination with a spike in the number of lung cancer cases in never smokers, this ensures that lung cancer will remain a major health problem [3]. Lung cancer is clinically divided into two subtypes, small cell lung cancer (SCLC) and non-small cell lung cancer (NSCLC). The latter is the most common type, accounting for $85-90 \%$ of the total cases [3]. Although recent studies have shown that adjuvant chemotherapy improves survival in completely resected NSCLC $[4,5]$, only $5-15 \%$ of treated individuals ultimately benefit [6].

\section{Biomed Central}


Despite the fact that the cause of most lung cancer is well know, the disease has proven difficult to diagnosis early and treat successfully, reflecting limited advances in our understanding of the molecular mechanisms underlying lung carcinogenesis.

Currently, mutations in the K-ras oncogene, p53 tumor suppressor gene, and epidermal growth factor receptor $(E G F R)$ gene have been found frequently in lung tumors and implicated in lung carcinogenesis [7-9]. In addition, genomic abnormalities represent another major signature of neoplastic transformation and tumor progression [10]. Chromosome copy number abnormalities in lung cancer have been frequently identified using comparative genomic hybridization $(\mathrm{CGH})$ assay $[11,12]$, including genomic amplification of PIK3CA which codes the phosphatidylinositol-3-kinase (PI3K) catalytic subunit $\alpha$ [13]. PIK3CA is generally activated by a series of cell surface tyrosine kinase receptors [14]. Upon activation, PIK3CA binds to its heterodimer, p85, and promotes the phosphorylation of Akt. Activated Akt phosphorylates down-stream protein effectors and amplifies the signaling cascade, enhancing cell proliferation and survival [15]. The previous studies have shown that PIK3CA amplification was more frequently observed in squamous cell carcinomas (SCC) than adenocarcinomas (ADC), which was closely associated with increased Akt activity in SCC $[12,13]$, suggesting that PIK3CA amplification, in addition to $K$-ras and EGFR mutations, may be another major cause of overactivation of PI3K/Akt pathway that promotes lung tumorigenesis.

In addition to genetic factors, promoter methylation is an alternative mechanism underlying inactivation of tumor-associated genes in lung carcinogenesis $[16,17]$. Currently, methylated gene profiles have been widely studied in lung cancer $[18,19]$. Of note, although it has been suggested that epigenetic alterations of genes can occur as a consequence of, or coexist with, aberrant signaling of certain oncogenic pathways activated by genetic alterations, such as PIK3CA amplification, EGFR mutation and $K$-ras mutation [20,21], the interaction between genetic and epigenetic alterations in lung cancer still remains poorly understood.

In the present study, we used quantitative methylation-specific PCR (Q-MSP) to evaluate methylation levels of a panel of cancer-related genes in a cohort of clinically well-characterized NSCLC samples, including CALCA, CDH1, DAPK1, EVX2, PAX6, and RASSF1A, and further explore the association of promoter methylation of these genes with PIK3CA amplification.

\section{Methods}

\section{Clinical samples and DNA isolation}

With the institutional review board approval, 96 tissue samples from 96 NSCLC patients and 15 controls from non-cancerous respiratory diseases, including 6 patients with pulmonary tuberculosis, 4 patients with brochiectasis and 5 patients with pulmonary abscess, were randomly obtained from the First Affiliated Hospital of China Medical University, P.R. China. Of these controls, the mean age was 60.7 years, and over 60 years of age accounts for $47 \%$. Sixty-seven percent of controls were male. Seventy-three percent of controls had a history of smoking. The clinicopathologic characteristics of NSCLC cases are shown in Table 1 . None of these NSCLC patients received chemotherapy and radiotherapy before the surgery. Informed consent was obtained from each NSCLC patient before the surgery. All of the

Table 1 Clinicopathologic features of NSCLC cases

\begin{tabular}{lc}
\hline Characteristics & No. of patients (\%) \\
\hline Gender & $66(69)$ \\
Male & $30(31)$ \\
Female & \\
Age (mean years \pm S.D.) & $58.9 \pm 9.2$ \\
$\leq 60$ & $56(58)$ \\
$>60$ & $40(42)$ \\
Smoking history & \\
No & \\
Yes & $30(31)$ \\
& $66(69)$ \\
Tumor size (mean cm \pm S.D.) & \\
$1-3$ & $3.9 \pm 1.7$ \\
$3-5$ & $37(38)$ \\
$>5$ & $44(46)$
\end{tabular}

Histologic type

Adenocarcinoma (ADC) 30 (31)

Squamous (SSC)

66 (69)

Histologic stage

।

II

$54(56)$

$\|$

$32(34)$

$10(10)$

Lymph node metastasis

No

$70(73)$

Yes

26 (27)

\begin{tabular}{|c|c|}
\hline \multicolumn{2}{|c|}{ Pleural indentation } \\
\hline No & 75 (78) \\
\hline Yes & $21(22)$ \\
\hline \multicolumn{2}{|c|}{ Invasion or Adhesion } \\
\hline No & 65 (68) \\
\hline Yes & $31(32)$ \\
\hline
\end{tabular}


samples were reviewed by a pathologist at Department of Pathology of the Hospital to identify histologic type and other tumor characteristics. The samples were treated and genomic DNA was isolated from paraffinembedded tissues as previously described [22], using xylene to remove pareffin and sodium dodecyl sulfate (SDS) and proteinase $\mathrm{K}$ to digest tissues, followed by phenol-chloroform extraction and ethanol precipitation of DNA.

\section{Sodium bisulfite treatment}

Bisulfite processing of DNA was performed in principle as described previously [20]. Briefly, a final volume of $20 \mu \mathrm{l}$ of $\mathrm{H}_{2} \mathrm{O}$ containing $2 \mu \mathrm{g}$ genomic DNA, $10 \mu \mathrm{g}$ salmon sperm DNA, and $0.3 \mathrm{M} \mathrm{NaOH}$ was incubated at $50^{\circ} \mathrm{C}$ for $20 \mathrm{~min}$ to denature the DNA. The bisulfite reaction was performed in $500 \mu \mathrm{l}$ of a freshly prepared solution containing $3 \mathrm{M}$ sodium bisulfite (Sigma, Saint Louis, MO), $10 \mathrm{mM}$ hydroquinone (Sigma, Saint Louis, $\mathrm{MO})$ at $70^{\circ} \mathrm{C}$ for $2-3 \mathrm{~h}$. DNA was subsequently recovered by a Wizard DNA Clean-Up System (Promega Corp., Madison, WI) following the instructions of the manufacturer, and desulphonated in $0.2 \mathrm{M} \mathrm{NaOH}$ at $37^{\circ} \mathrm{C}$ for 10 minutes, neutralized by ammonium acetate, alcohol precipitated, dried, and then dissolved in $30 \mu \mathrm{l}$ of deionized $\mathrm{H}_{2} \mathrm{O}$. After bisulfite processing, all unmethylated cytosine residues converted to uracil, whereas the methylated cytosine residues remained unchanged. Bisulfited-modified DNA samples were stored at $-80^{\circ} \mathrm{C}$ until use.

\section{Quantitative methylation-specific PCR (Q-MSP) assay}

The Q-MSP protocol was as described previously [20]. Briefly, the Q-MSP assay was carried out in a final volume of $20 \mu \mathrm{l}$ on a 96-well plate using an ABI 7500 Fast Real-Time PCR System (Perkin-Elmer, Foster City, $\mathrm{CA})$. The reaction mixture contained $3 \mu \mathrm{l}$ bisulfite-treated DNA, $600 \mathrm{nM}$ each primer, $200 \mathrm{nM}$ TaqMan probe, $5.5 \mathrm{mM} \mathrm{MgCl}$ 2, $0.6 \mathrm{U}$ platinum Taq polymerase, 200 $\mu \mathrm{M}$ each of deoxyguanosine triphosphate, and $2 \%$ Rox reference. Q-MSP was run at $95^{\circ} \mathrm{C}$ for $2 \mathrm{~min}$, followed by 40 cylces at $95^{\circ} \mathrm{C}$ for $15 \mathrm{sec}$ and $60^{\circ} \mathrm{C}$ for $1 \mathrm{~min}$.
Each sample was run in triplicate and each plate contained multiple water blanks and serial dilutions of positive methylated controls to construct the standard curve. Methylated DNA samples, used as positive controls, were obtained by in vitro treatment of leukocyte DNA with Sss I DNA methylase (New Engliand Biolabs, Beverly, MA). To determine the relative level of methylation, the ratio of the value of the gene of interest over the value of the internal reference gene ( $\beta$-actin) was used in the current detection system. The primers and TaqMan probes used in the present study were presented in Table 2.

\section{Copy number analysis of PIK3CA with real-time quantitative PCR}

We used a real-time quantitative PCR technique to analyze the copy number of PIK3CA gene on an ABI 7500 Fast Real-Time PCR System (Perkin-Elmer, Foster City, CA) as described previously [22]. This method was well established and validated by florescence in situ hybridization (FISH) [22,23], which has been widely used in the various cancers [22-25]. Specific primers and probes were designed using Primer Express 3.0 (Applied Biosystems) to amplify PIK3CA and $\beta$-actin genes as described previously [22]. The reaction of quantitative PCR was repeated twice, and $\beta$-actin was run in parallel to normalize the amount of input DNA. A standard curve was established using serial dilutions of normal leukocyte DNA with a quantity range of 0.01-20 ng/ $\mu \mathrm{l}$. Amplification of PIK3CA gene was defined by a copy number $\geq 4$.

\section{Statistical analysis}

A methylation positive result was defined when the ratio was above a certain cut-off value. The relative level of methylation varied significantly among the 6 genes and the cut-off points were thus studied for each gene individually. To define cut-off value of each gene, we construct receiver operating characteristic (ROC) curves using the Medcalc Software (MedCalc Software bvba, Belgium). The area under ROC curve is a measure of the ability of a continuous marker to

Table 2 Quantitative methylation-specific PCR primer and TaqMan probe sequences used in the present study

\begin{tabular}{|c|c|c|c|}
\hline Genes & Forward primer sequence $\left(5^{\prime} \rightarrow 3^{\prime}\right)$ & Probe sequence $\left(5^{\prime} \rightarrow 3^{\prime}\right)$ & Reverse primer sequence $\left(5^{\prime} \rightarrow 3^{\prime}\right)$ \\
\hline$A L C A$ & GTIT & 6FAM-ATTCCGCCAATACACAACAACCAATAAACG-TAMRA & TTCCCGCCGCTATAAATCG \\
\hline $\mathrm{CDH1}$ & AATTTAGGTTAGAGGGTTATCGCGT & 6FAM-CGCCCACCCGACCTCGCAT-TAMRA & TCCCCAAAACGAAACTAACGAC \\
\hline DAPK1 & GGATAGTCGGATCGAGTTAACGTC & 6FAM-TTCGGTAATTCGTAGCGGTAGGGTTTGG-TAMRA & CCCTCCCAAACGCCGA \\
\hline EVX2 & TCGTTGGCGGGTGGGTATAG & 6FAM-CTTCACTCCAAACCGCTCCTCATCTCCCG-TAMRA & ACGCCGATAACAACCAT \\
\hline PAX6 & ATATAGGACGGCGGTTTAGGTTG & 6FAM-CCCAAAATCCGACCGACTCCAACCCCTA-TAMRA & TTCCGACCGAACGAAAACCTAC \\
\hline RASSF1A & GCGTTGAAGTCGGGGTTC & 6FAM-ACAAACGCGAACCGAACGAAACCA-TAMRA & CCCGTACTTCGCTAACTTTAAACG \\
\hline 3-Actin & TGGTGATGGAGGAGGTITAGTAAGT & 6FAM-ACCACCACCCAACACACAATAACAAACACA-TAMRA & AACCAATAAAACCTACTCCTCCCTTAA \\
\hline
\end{tabular}


accurately classify tumor and non-tumor tissue. Such a curve is a plot of sensitivity vs. 100 minus specificity values associated with all dichotomous markers that can be formed by varying the cut-off values used to define a marker "positive". As an useful biomarker for early diagnosis and prognostic evaluation of diseases, its specificity should be more important than its sensitivity. Hence, in the present study, cut-offs were obtained in order to achieve $100 \%$ specificity. Factors (promoter methylation and PIK3CA amplification) associated with clinicopathological characteristics of tumor were assessed univariately using the Medcalc Software (MedCalc Software bvba, Belgium). Similarly, univariate models were examined the association between gene methylation and PIK3CA amplification. Multivariate models were then developed that adjusted for the most important covariates, including smoking history, histologic type, and lymph node metastasis. Sample means were compared using unpaired $t$-test, assuming unequal variances, and all tests were twotailed. $P$ values $<0.05$ were considered significant. All statistical analyses were performed using the SPSS statistical package (11.5, Chicago, IL, USA).

\section{Results}

\section{NSCLC patient profiles}

In the present study, we analyzed the promoter methylation of 6 genes using Q-MSP technique in 96 well-characterized NSCLC patients. As shown in Table 1, the mean age of all NSCLC cases was 58.9 years, and the cases with age $>60$ years accounts for $42 \%$. Males were more frequent than females (69\% vs. 31\%). Sixty-nine percent of cases had a history of smoking. Ninety percent of NSCLC cases had surgical stage I and II disease and $84 \%$ had tumors $<5 \mathrm{~cm}$. By histology, $31 \%$ of patients were ADC, and 69\% were SCC. The cases with lymph node metastasis, pleural indentation and invasion or adhesion were in 26/96 (27\%), 21/96 (22\%), and 31/ $96(32 \%)$, respectively.

\section{Frequent promoter methylation and PIK3CA amplification in NSCLC}

We used Q-MSP assay to examine promoter methylation of CALCA, CDH1, DAPK1, EVX2, PAX6, and RASSF1A genes in a large cohort of NSCLC samples. As shown in Figure 1, the overall methylation level of each of 6 genes was higher in NSCLC tissues than in noncancerous lung tissues, particularly CALCA $(P<0.01)$, CDH1 $(P<0.01)$, EVX2 $(P<0.01)$, PAX6 $(P<0.001)$, and RASSF1A $(P<0.05)$. To distinguish NSCLC from non-cancerous lung tissues, we set up appropriate cutoff values, and used them to determine diagnostic sensitivity and specificity. As shown in Figure 2, with 100\% diagnostic specificity for each of the 6 genes, the sensitivity of CALCA,CDH1, DAPK1, EVX2, PAX6, and RASSF $1 A$ was $69.2 \%, 45.8 \%, 84.1 \%, 63.6 \%, 75.7 \%$, and $72.9 \%$, respectively. With a gene copy number of four or more defined as amplification, we found the incidence of PIK3CA amplification in NSCLC was $31.3 \%$ (30/96) in the present study. Of note, among all cases with PIK3CA amplification, only two cases were ADC, the remaining cases were SCC.

\section{Association of promoter methylaton and PIK3CA amplification with clinicopathological characteristics in NSCLC}

Among all clinicopathologic characteristics, promoter methylation was associated with histologic type (Figure $3)$. The univariate analyses showed that methylation of CALCA, CDH1, DAPK1, and EVX2 was common in $\mathrm{SCC}$ compared to ADC, particularly in $C D H 1(\mathrm{OR}=$ 2.63, 95\% CI $=1.05-6.60)$ and DAPK1 (OR $=6.64,95 \%$ $\mathrm{CI}=1.85-23.8)$ (Figure 3$)$. Conversely, there was a trend toward a higer frequency of RASSF1A methylation in ADC than SCC (Figure 3). Moreover, there was a trend toward a positive association between CALCA methylation and invasion or adhesion $(\mathrm{OR}=2.44,95 \%$ $\mathrm{CI}=0.88-6.79)$. Similarly, there was a trend toward a higher frequency of $D A P K 1$ methylaton in patients with lymph node metastasis than without metastasis $(\mathrm{OR}=5.17,95 \% \mathrm{CI}=0.64-42.0)$ (Figure 3). Of interest, RASSF1A methylation was negatively associated with smoking history, lymph node metastasis, and invasion or adhesion, respectively, although these associations did not reach statistical difference (Figure 3), suggesting that RASSF1A methylation may be an early event in lung tumorigenesis, which further confirmed a previous study. However, no association was found between promoter methylation and other clinocopathologic characteristics, including gender, age, quantity of cigarette smoking, tumor size, and pleural indentation (data not shown).

Similar to a previous study [25], PIK3CA gene was more frequently amplified in NSCLC, and was not amplified in non-cancerous lung tissues in the present study. The results showed that there was a trend toward a higher frequency of PIK3CA amplification in males than females (24/66 in males and 6/30 in females) (Figure 4). PIK3CA amplification was significantly frequent in smokers compared to never-smokers (25/66 in smokers and 5/30 in never-smokers; OR $=3.05,95 \% \mathrm{CI}=$ 1.03-8.90), and in SCC compared to in ADC (28/66 in $\mathrm{SCC}$ and $2 / 30$ in $\mathrm{ADC} ; \mathrm{OR}=10.3,95 \% \mathrm{CI}=2.27-47.0$ ) (Figure 4 ). Of note, there was a trend toward a negative association between PIK3CA amplification and pleural indentation in NSCLC (Figure 4). 


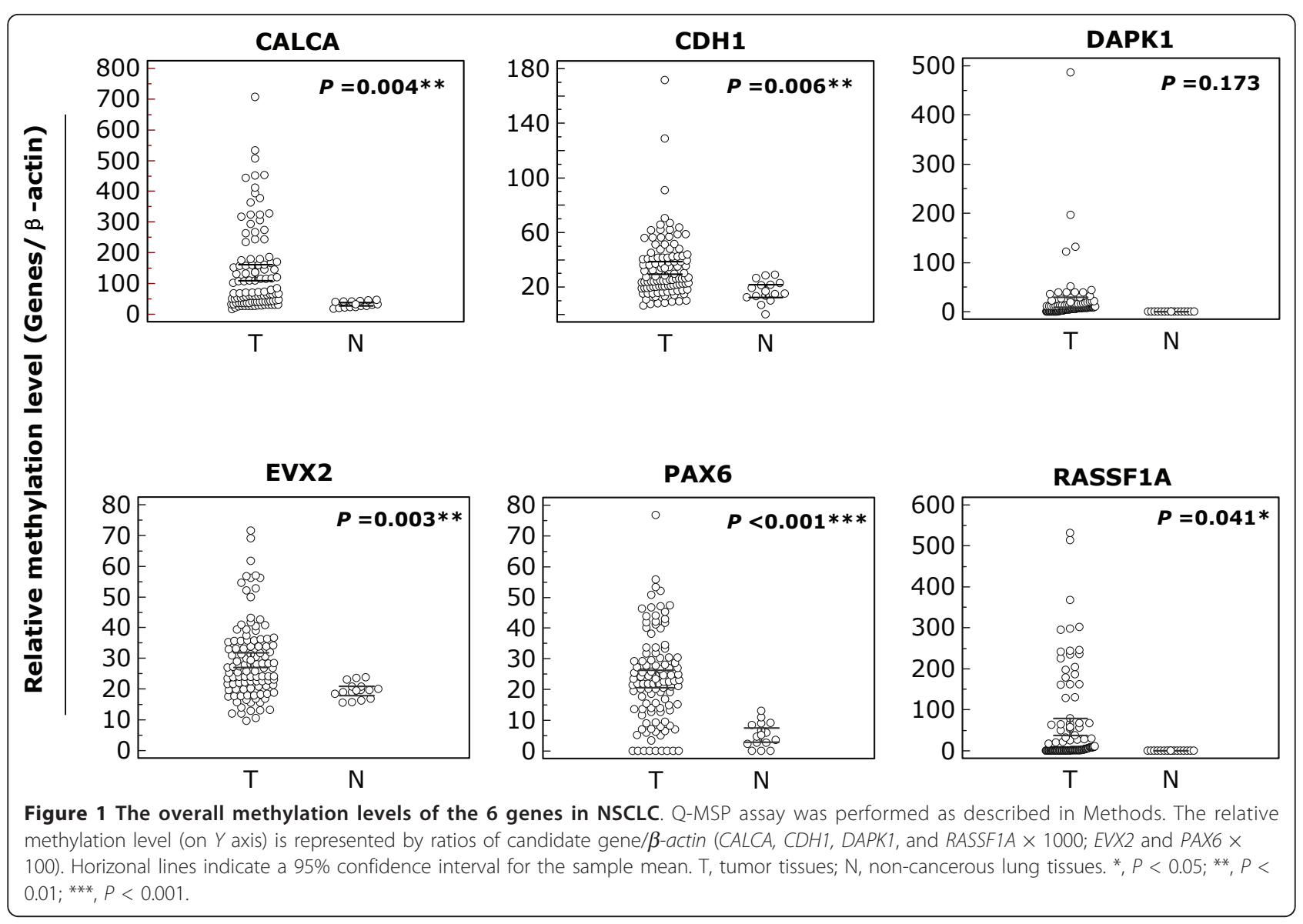

\section{Association of promoter methylation with PIK3CA amplification in NSCLC}

To explore the relationship between promoter methylation with PIK3CA amplification in NSCLC, all tumor samples were divided into two groups, one with PIK3CA amplification and the other without PIK3CA amplification. As shown in Figure 5, methylation level of $C A L C A$ $(P=0.0006)$ and $E V X 2(P=0.001)$ was significantly higher in the former group than in the latter group. However, there was not significant association between $P I K 3 C A$ amplification and methylation level of other genes, including CDH1, DAPK1, PAX6, and RASSF1A (Figure 5), suggesting a specific association of $P I K 3 C A$ amplification with methylation of CALCA and EVX2 in NSCLC.

Univariate analyses indicated that promoter methylation of CALCA was significantly positively associated with $P I K 3 C A$ amplification $(\mathrm{OR}=3.05,95 \% \mathrm{CI}=1.03$ 8.99). Conversely, promoter methylation of $P A X 6$ was significantly negatively associated with PIK3CA amplification $(\mathrm{OR}=0.27,95 \% \mathrm{CI}=0.10-0.72)$. In order to assess the independent associations between promoter methylation of these genes and PIK3CA amplification, smoking history, histologic type, and lymph node metastasis, we conducted multiple multivariable logistic regressions (Table 3). Similarly, the results showed that there was a trend toward a positive association between CALCA methylation and PIK3CA amplification $(\mathrm{OR}=$ 2.55, 95\% CI $=0.81-8.08)$. Promoter methylation of $P A X 6$ was significantly negatively associated with PIK3CA amplification $(\mathrm{OR}=0.19,95 \% \mathrm{CI}=0.06-0.62)$ (Table 3).

\section{Discussion}

In the present study, we investigated the promoter methylation of the 6 genes in a large cohort of wellcharacterized NSCLC samples using Q-MSP technique and their relationships to PIK3CA amplification. Promoter methylation of these genes, as a mechanism for their silencing, has been frequently observed in NSCLC, particularly CALCA, CDH1, DAPK1, and RASSF1A [26-28]. In addition, this study also involved two new methylation markers, EVX2 and PAX6, which were highly specific for tumor-associated methylation, and little or no methylation was observed in tumor-adjacent normal lung tissue [29]. Our findings showed that the overall methylation level from 5 of 6 genes in tumor tissues was significant higher than in non-cancerous lung 


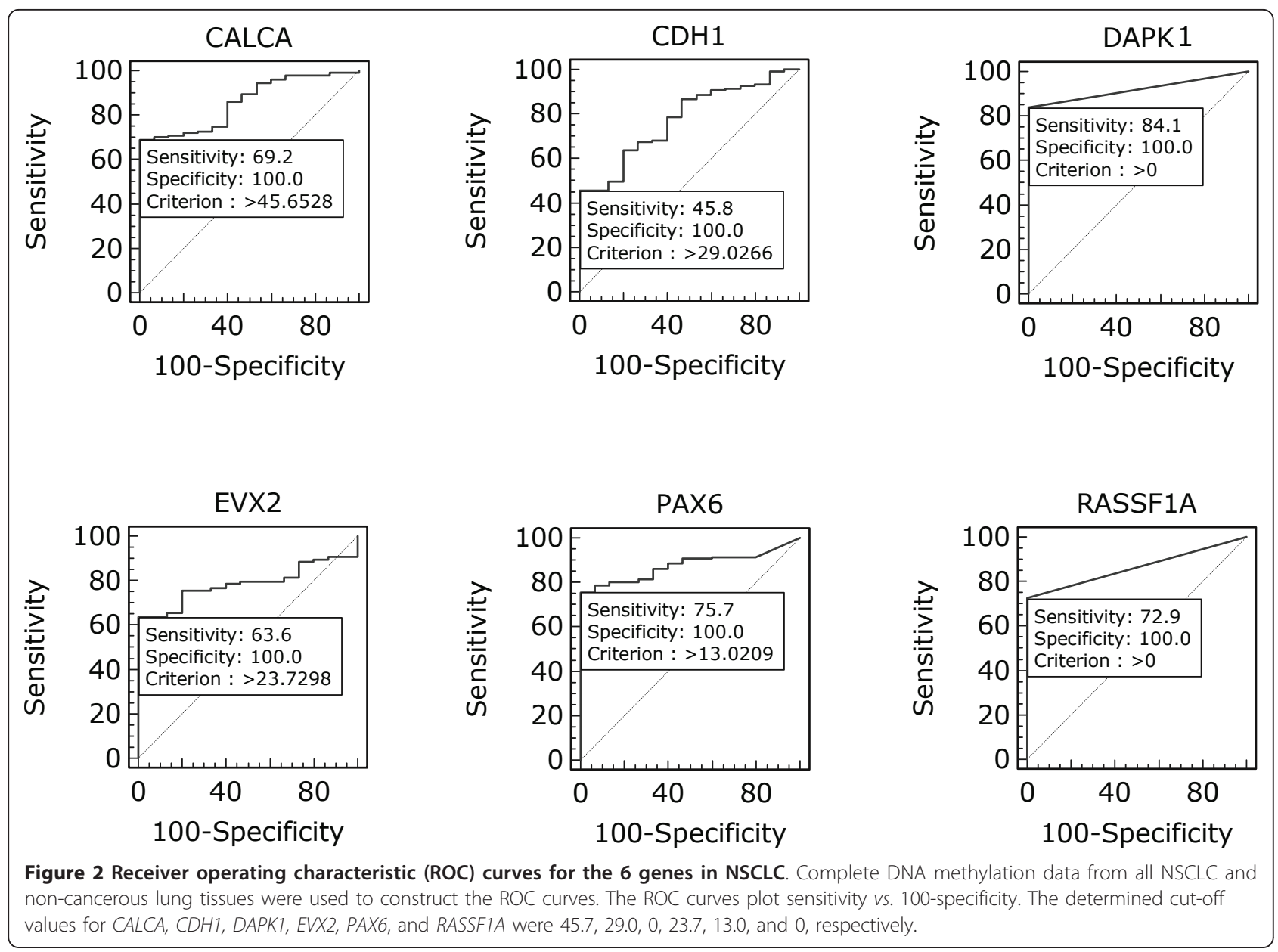

tissues, including CALCA, CDH1, EVX2, PAX6, and RASSF1A. With $100 \%$ diagnostic specificity, excellent sensitivity, ranging from 45.8 to $84.1 \%$, was obtained for each of the 6 genes. However, the analysis of hypermethylation still had a limitation in the present study, which the values of hypermethylation were not established a priori, but were calculated to maximize sensitivity given $100 \%$ specificity, the resulting sensitivities might be biased overestimates. To obtain non-biased sensitivity (and specificity) values, cut-offs need to be validated in a separate independent sample. In the present study, we also observed that promoter methylation of certain genes was associated with histologic type. Methylation of CALCA, CDH1, DAPK1, and EVX2 was common in SCC compared to ADC, particularly in CDH1 (OR $=2.63,95 \% \mathrm{CI}=1.05-6.60)$ and DAPK1 $(\mathrm{OR}=6.64,95 \% \mathrm{CI}=1.85-23.8)$. Conversely, there was a trend toward a higher frequency of RASSF1A methylation in ADC than SCC, which is consistent with a recent study [26]. Of note, there was a trend toward an association between methylation of CALCA and DAPK1 and invasion or adhesion and lymph node metastasis, suggesting that aberrant methylation of these genes is associated with oncologic outcomes of NSCLC patients. Similar to a previous study [30], RASSF1A methylation was negatively associated with smoking history, lymph node metastasis, and invasion or adhesion, respectively. In addition, RASSF1A was more frequently methylated in early tumor stage (data not shown), suggesting that RASSF $1 A$ methylation may be an early event in lung tumorigenesis.

Although tobacco smoking plays a dominant role in the development of lung cancer, we did not observe significant association between promoter methylation and smoking history in the present study, in agreement with most studies [31-34]. However, several studies have reported aberrant methylation of tumor-related genes was associated with tobacco smoking [32,35,36]. It is possible that smoking-associated lung cancer is complex disease which involved many unique genetic and epigenetic events. Thus, better understanding of the molecular mechanisms underlying this disease would undoubtedly improve the outcomes of such patients. 


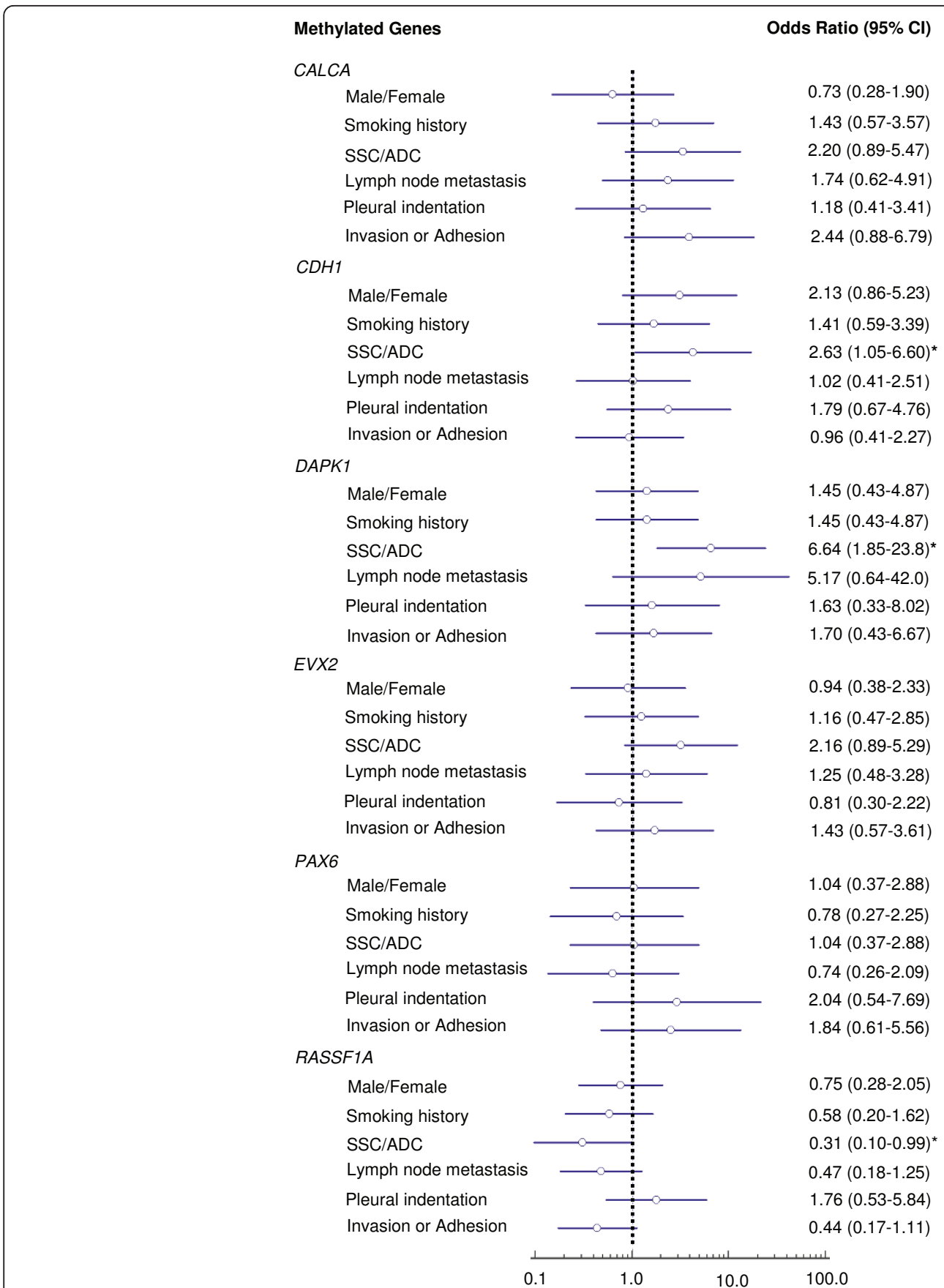

Figure 3 Relationship of promoter methylation (Odds Ratios) with tumor characteristics of NSCLC. Multiple univariate logistic-regressions were performed with the use of methylation data for the 6 genes that were defined as 'positive' or 'negative' through receiver operating characteristic (ROC) curves. Details are as described in Methods. ${ }^{*}, P<0.05$.

It has recently become clear that PI3K/Akt pathway is frequently activated in human cancers [15,37], and plays an important role in the regulation of cell growth, proliferation, and survival and is involved in human tumorigenesis [15]. In recent years, many oncologists have mainly focused on PIK3CA. In addition to PIK3CA mutations [38,39], PIK3CA amplification was frequently found in lung cancer, and promoted lung tumorigenesis through overactivation of PI3K/Akt signaling pathway $[12,13,25,39]$. Similar to the previous studies, in the present study, we found high frequency of PIK3CA amplification in Chinese NSCLC population. Moreover, PIK3CA amplification was significantly associated with smoking history and histologic type, which was more 

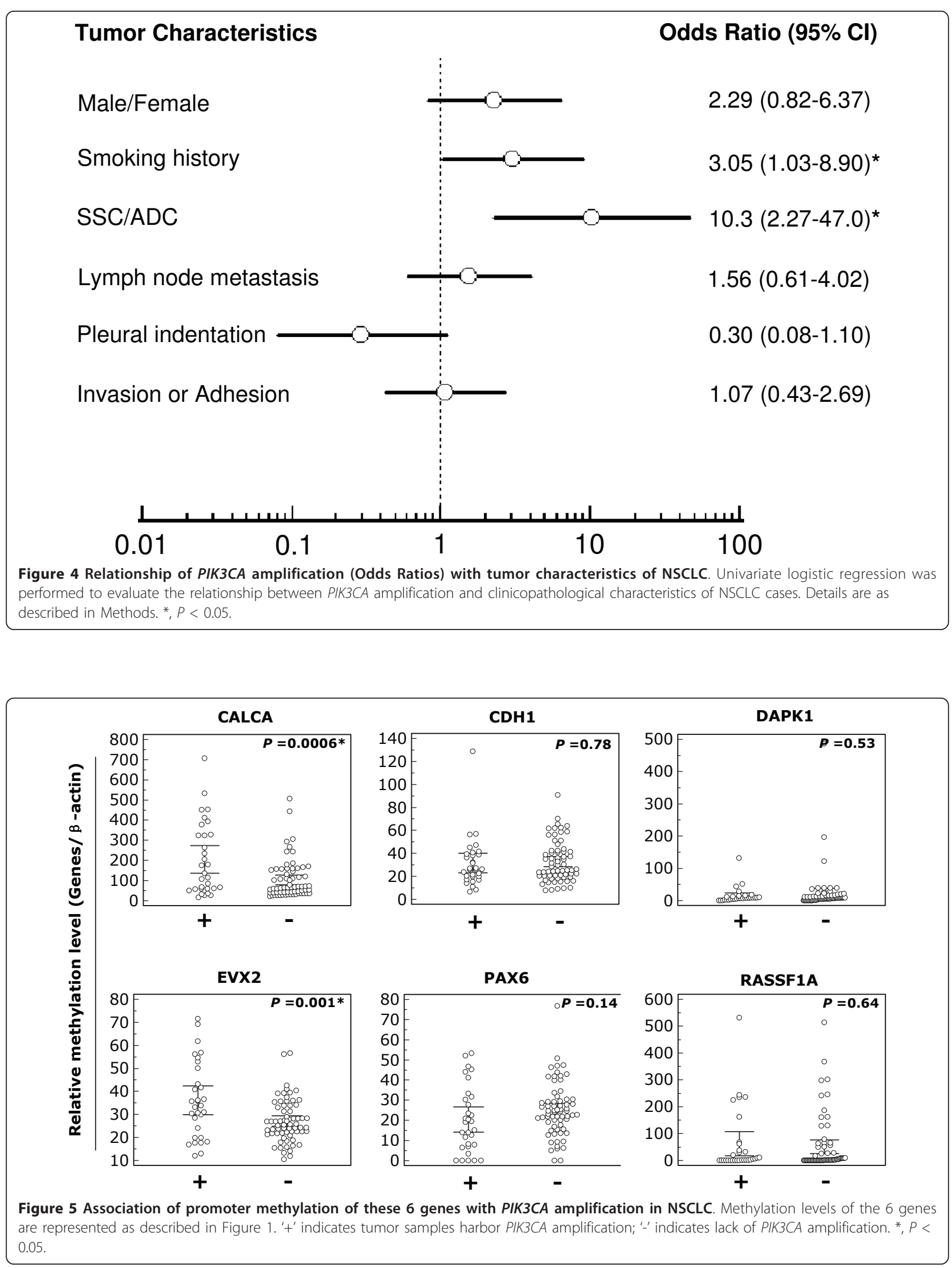
Table 3 Promoter methylation of individual genes in NSCLC - multivariable models assessing PIK3CA amplification, smoking history, histologic type, and lymph node metastasis $\left(\mathrm{OR}^{\dagger}\right.$ and $\left.95 \% \mathrm{Cl}\right)$

\begin{tabular}{lcccc}
\hline Genes & PIK3CA amplification & Smoking history & SSC vs. ADC & Lymph node metastasis \\
\hline CALCA & $2.55(0.81-8.08)$ & $1.08(0.41-2.84)$ & $1.46(0.51-4.16)$ & $1.38(0.44-4.31)$ \\
\hline CDH1 & $0.42(0.16-1.12)$ & $1.35(0.52-3.47)$ & $4.01(1.37-11.79)^{*}$ & $0.64(0.24-1.75)$ \\
\hline DAPK1 & $0.59(0.11-3.15)$ & $1.45(0.39-5.30)$ & $6.09(1.25-29.66)^{*}$ & $2.26(0.24-21.44)$ \\
\hline EVX2 & $1.31(0.47-3.69)$ & $0.94(0.36-2.43)$ & $2.06(0.73-5.84)$ & $0.92(0.32-2.65)$ \\
\hline PAX6 & $0.19(0.06-0.62)^{*}$ & $0.97(0.31-3.11)$ & $2.62(0.68-10.14)$ & $0.62(0.19-2.05)$ \\
\hline RASSF1A & $1.63(0.57-4.70)$ & $0.65(0.22-1.95)$ & $0.32(0.09-1.18)$ & $0.67(0.24-1.87)$ \\
\hline TER Odd
\end{tabular}

† OR: odds ratio with $95 \%$ confidence interval, adjusted for multiple comparisions.

* Significant at $P<0.05$.

frequent in smokers compared to never-smokers, and in SCC compared to in ADC. Of note, although no statistical difference was noted, PIK3CA amplification was negatively associated with pleural indentation in NSCLC. However, pleural indentation is a well-known imaging sign on chest computed tomography (CT) that suggests a possible pleural invasion by peripheral NSCLC, particularly ADC $[40,41]$. Importantly, pleural involvement was significantly correlated with a poor prognosis in NSCLC, suggesting that pleural involvement may be one of most important factors to affect on the prognosis of NSCLC [42]. One possibility to explain this contradiction is that, PIK3CA gene was more frequently amplified in SCC, not ADC, whereas pleural indentation is more common in ADC.

It has been suggested the epigenetic alterations might addict cells to certain oncogenic pathways, predisposing cells to the accumulations of genetic mutations, which drives tumor progression [43]. On the other hand, overactivation of certain oncogenic pathways can affect the activity of methytransferase, and potentially the methylation activity and regulation of gene transcription, such as RAS/RAF/MEK/ERK pathway (MAPK pathway) [44-47]. Recently, a number of tumor-related genes were found to be aberrantly methylated in association with the MAPK pathway overactivated by $B R A F$ mutation in human cancers, such as $h M L H 1$ in colon cancer [48], and SLC5A8 in thyroid cancer [49]. Of note, our previous study showed that PTEN gene was aberrantly methylated in association with activating genetic alterations in PI3K/Akt pathway, including PIK3CA amplification [20]. Moreover, another study showed that the differences in the evolvement of epigenetic alterations between the EGFR and K-ras mutation-mediated tumorigenesis and suggested that the specific interation of genetic and epigenetic events in lung tumorigenesis [21]. In the present study, we found that promoter methylation of CALCA, EVX2, and PAX6 was significantly associated with $P I K 3 C A$ amplification in NSCLC, however, such association was not seen with other gene methylation, suggesting that epigenetic alterations of these three genes may specifically occur as a consequence of overactivation of PI3K/Akt pathway in NSCLC.

\section{Conclusions}

In summary, the results of the present study provided evidence that multiple genes were aberrantly methylated during the process of lung tumorigenesis. We found highly frequent PIK3CA amplification in Chinese NSCLC cases, but not in non-cancerous lung tissues, implicating PI3K/Akt pathway in lung tumorigenesis. Importantly, we have the first time revealed significant associations of gene methylation with PIK3CA amplification in NSCLC, which is consistent with a model which aberrant methylation and hence silencing of a number of tumor-related genes, which coexisted with activating genetic alterations of PI3K/Akt pathway, may be a consequence of overactivation of this pathway. Further studies are needed to explore the molecular mechanisms underling the link between such genetic and epigenetic events.

\section{Acknowledgements}

This work was supported by the National Natural Science Foundation of China (No. 30901459 and 30973372) and the Fundamental Research Funds for the Central Universities.

\section{Author details}

${ }^{1}$ Department of Endocrinology, The First Affiliated Hospital of Xi'an Jiaotong University College of Medicine, Xi'an 710061, the People's Republic of China. ${ }^{2}$ Department of Endocrinology and Metabolism, The First Affiliated Hospital of China Medical University, Shenyang 110001, the People's Republic of China.

\section{Authors' contributions}

MJ and PH conceived and designed the experiments. MJ, HG and CG performed the experiments. MJ and $\mathrm{PH}$ collected the samples and analyzed the data. BS and $\mathrm{PH}$ contributed reagents/materials/analysis tools. MJ and $\mathrm{PH}$ Wrote the paper. All authors are in agreement with the content of the manuscript and this submission.

\section{Competing interests}

The authors declare that they have no competing interests. 
Received: 12 July 2010 Accepted: 20 April 2011 Published: 20 April 2011

\section{References}

1. Song F, He M, Li H, Qian B, Wei Q, Zhang W, Chen K, Hao X: A cancer incidence survey in Tianjin: the third largest city in China-between 1981 and 2000. Cancer Causes Control 2008, 19:443-450.

2. Yang L, Parkin DM, Li LD, Chen YD, Bray F: Estimation and projection of the national profile of cancer mortality in China: 1991-2005. Br J Cancer 2004, 90:2157-2166.

3. Molina JR, Yang P, Cassivi SD, Schild SE, Adjei AA: Non-small cell slung cancer: epidemiology, risk factors, treatment, and survivorship. Mayo Clin Proc 2008, 83:584-594.

4. Kato H, Ichinose $\mathrm{Y}$, Ohta M, Hata E, Tsubota N, Tada H, Watanabe $\mathrm{Y}$, Wada H, Tsuboi M, Hamajima N, et al: Japan Lung Cancer Research Group on Postsurgical Adjuvant Chemotherapy. A randomized trial of adjuvant chemotherapy with uracil-tegafur for adenocarcinoma of the lung. $N$ Engl J Med 2004, 350:1713-1721.

5. Winton T, Livingston R, Johnson D, Rigas J, Johnston M, Butts C, Cormier Y, Goss G, Inculet R, Vallieres E, et al: National Cancer Institute of Canada Clinical Trials Group; National Cancer Institute of the United States Intergroup JBR.10 Trial Investigators. Vinorelbine plus cisplatin vs. observation in resected non-small-cell lung cancer. N Eng/J Med 2005, 352:2589-2597.

6. Hotta K, Matsuo K, Ueoka H, Kiura K, Tabata M, Tanimoto M: Role of adjuvant chemotherapy in patients with resected non-small-cell lung cancer: reappraisal with a meta-analysis of randomized controlled trials. J Clin Oncol 2004, 22:3860-3867.

7. Keohavong P, DeMichele MA, Melacrinos AC, Landreneau RJ, Weyant RJ, Siegfried JM: Detection of K-ras mutations in lung carcinomas: relationship to prognosis. Clin Cancer Res 1996, 2:411-418.

8. Le Calvez F, Mukeria A, Hunt JD, Kelm O, Hung RJ, Tanière P, Brennan P, Boffetta P, Zaridze DG, Hainaut P: TP53 and KRAS mutation load and types in lung cancers in relation to tobacco smoke: distinct patterns in never, former, and current smokers. Cancer Res 2005, 65:5076-5083.

9. Kosaka T, Yatabe Y, Endoh H, Kuwano H, Takahashi T, Mitsudomi T: Mutations of the epidermal growth factor receptor gene in lung cancer: biological and clinical implications. Cancer Res 2004, 64:8919-8923.

10. Gray JW, Collins C: Genome changes and gene expression in human solid tumors. Carcinogenesis 2000, 21:443-452.

11. Balsara BR, Sonoda G, du Manoir S, Siegfried JM, Gabrielson E, Testa JR: Comparative genomic hybridization analysis detects frequent, often high-level, overrepresentation of DNA sequences at $3 q, 5 p, 7 p$, and $8 q$ in human non-small cell lung carcinomas. Cancer Res 1997, 57:2116-2120.

12. Bjorkqvist AM, Husgafvel-Pursiainen K, Anttila S, Karjalainen A, Tammilehto L, Mattson K, Vainio H, Knuutila S: DNA gains in 3q occur frequently in squamous cell carcinoma of the lung, but not in adenocarcinoma. Genes Chromosomes Cancer 1998, 22:79-82.

13. Massion PP, Kuo WL, Stokoe D, Olshen AB, Treseler PA, Chin K, Chen C, Polikoff D, Jain AN, Pinkel D, et al: Genomic copy number analysis of nonsmall cell lung cancer using array comparative genomic hybridization: implications of the phosphatidylinositol 3-kinase pathway. Cancer Res 2002, 62:3636-3640.

14. Vanhaesebroeck B, Stein RC, Waterfield MD: The study of phosphoinositide 3-kinase function. Cancer Surv 1996, 27:249-270.

15. Vivanco I, Sawyers CL: The phosphatidylinositol 3-Kinase AKT pathway in human cancer. Nat Rev Cancer 2002, 2:489-501.

16. Palmisano WA, Divine KK, Saccomanno G, Gilliland FD, Baylin SB, Herman JG, Belinsky SA: Predicting lung cancer by detecting aberrant promoter methylation in sputum. Cancer Res 2000, 60:5954-5958.

17. Risch A, Plass C: Lung cancer epigenetics and genetics. Int J Cancer 2008, 123:1-7.

18. Zochbauer-Muller S, Fong KM, Virmani AK, Geradts J, Gazdar AF, Minna JD: Aberrant promoter methylation of multiple genes in non-small cell lung cancers. Cancer Res 2001, 61:249-255.

19. Safar AM, Spencer H, Su X, Coffey M, Cooney CA, Ratnasinghe LD, Hutchins LF, Fan CY: Methylation profiling of archived non-small cell lung cancer: a promising prognostic system. Clin Cancer Res 2005, 11:4400-4405.

20. Hou P, Ji M, Xing M: Association of PTEN gene methylation with genetic alterations in the phosphatidylinositol 3-kinase/AKT signaling pathway in thyroid tumors. Cancer 2008, 113:2440-2447.
21. Toyooka S, Tokumo M, Shigematsu H, Matsuo K, Asano H, Tomii K, Ichihara S, Suzuki M, Aoe M, Date H, et al: Mutational and epigenetic evidence for independent pathways for lung adenocarcinomas arising in smokers and never smokers. Cancer Res 2006, 66:1371-1375.

22. Wu G, Mambo E, Guo Z, Hu S, Huang X, Gollin SM, Trink B, Ladenson PW Sidransky D, Xing M: Uncommon mutation, but common amplifications, of the PIK3CA gene in thyroid tumors. J Clin Endocrinol Metab 2005, 90:4688-4693.

23. Engelman JA, Zejnullahu K, Mitsudomi T, Song Y, Hyland C, Park JO, Lindeman N, Gale CM, Zhao X, Christensen J, et al: MET amplification leads to gefitinib resistance in lung cancer by activating ERBB3 signaling. Science 2007, 316:1039-1043.

24. Hou P, Liu D, Shan Y, Hu S, Studeman $K$, Condouris S, Wang Y, Trink A, ElNaggar AK, Tallini G, et al: Genetic alterations and their relationship in the phosphatidylinositol 3-kinase/Akt pathway in thyroid cancer. Clin Cancer Res 2007, 13:1161-1170.

25. Kawano O, Sasaki H, Okuda K, Yukiue H, Yokoyama T, Yano M, Fujii Y: PIK3CA gene amplification in Japanese non-small cell lung cancer. Lung Cancer 2007, 58:159-160.

26. Hawes SE, Stern JE, Feng Q, Wiens LW, Rasey JS, Lu H, Kiviat NB, Vesselle H: DNA hypermethylation of tumors from non-small cell lung cancer (NSCLC) patients is associated with gender and histologic type. Lung Cancer 2010, 69:172-179.

27. Wang Y, Zhang D, Zheng W, Luo J, Bai Y, Lu Z: Multiple gene methylation of nonsmall cell lung cancers evaluated with 3-dimensional microarray. Cancer 2008, 112:1325-1336.

28. Brock MV, Hooker CM, Ota-Machida E, Han Y, Guo M, Ames S, Glöckner S, Piantadosi S, Gabrielson E, Pridham G, et al: DNA methylation markers and early recurrence in stage I lung cancer. N Engl I Med 2008, 358:1118-1128.

29. Rauch TA, Zhong X, Wu X, Wang M, Kernstine KH, Wang Z, Riggs AD, Pfeifer GP: High-resolution mapping of DNA hypermethylation and hypomethylation in lung cancer. Proc Natl Acad Sci USA 2008, 105:252-257.

30. Honorio S, Agathanggelou A, Schuermann M, Pankow W, Viacava P, Maher ER, Latif F: Detection of RASSF1A aberrant promoter hypermethylation in sputum from chronic smokers and ductal carcinoma in situ from breast cancer patients. Oncogene 2003, 22:147-150.

31. Brabender J, Usadel H, Danenberg KD, Metzger R, Schneider PM, Lord RV, Wickramasinghe K, Lum CE, Park J, Salonga D, et al: Adenomatous polyposis coli gene promoter hypermethylation in non-small cell lung cancer is associated with survival. Oncogene 2001, 20:3528-3532.

32. Kim DH, Nelson HH, Wiencke JK, Zheng S, Christiani DC, Wain JC, Mark EJ, Kelsey KT: p16(INK4a) and histology-specific methylation of CpG islands by exposure to tobacco smoke in non-small cell lung cancer. Cancer Res 2001, 61:3419-3424.

33. Kim DH, Nelson HH, Wiencke JK, Christiani DC, Wain JC, Mark EJ, Kelsey KT: Promoter methylation of DAP-kinase: association with advanced stage in non-small cell lung cancer. Oncogene 2001, 20:1765-1770.

34. Sanchez-Cespedes M, Decker PA, Doffek KM, Esteller M, Westra WH, Alawi EA, Herman JG, Demeure MJ, Sidransky D, Ahrendt SA: Increased loss of chromosome $9 \mathrm{p} 21$ but not p16 inactivation in primary non-small cell lung cancer from smokers. Cancer Res 2001, 61:2092-2096.

35. Kersting M, Friedl C, Kraus A, Behn M, Pankow W, Schuermann M: Differential frequencies of p16(INK4a) promoter hypermethylation, p53 mutation, and K-ras mutation in exfoliative material mark the development of lung cancer in symptomatic chronic smokers. J Clin Oncol 2000, 18:3221-3229.

36. Toyooka S, Maruyama R, Toyooka KO, McLerran D, Feng Z, Fukuyama Y, Virmani AK, Zochbauer-Muller S, Tsukuda K, Sugio K, et al: Smoke exposure, histologic type and geography-related differences in the methylation profiles of non-small cell lung cancer. Int J Cancer 2003, 103:153-160.

37. Samuels Y, Ericson K: Oncogenic PI3K and its role in cancer. Curr Opin Oncol 2006, 18:77-82.

38. Kawano O, Sasaki H, Endo K, Suzuki E, Haneda H, Yukiue H, Kobayashi Y, Yano M, Fujii Y: PIK3CA mutation status in Japanese lung cancer patients. Lung Cancer 2006, 54:209-215.

39. Okudela K, Suzuki M, Kageyama S, Bunai T, Nagura K, Igarashi H, Takamochi K, Suzuki K, Yamada T, Niwa H, et al: PIK3CA mutation and amplification in human lung cancer. Pathol Int 2007, 57:664-671. 
40. Shapiro R, Wilson GL, Yesner R, Shuman H: A useful roentgen sign in the diagnosis of localized bronchioloalveolar carcinoma. Am J Roentgenol Radium Ther Nucl Med 1972, 114:516-524.

41. Kuhlman JE, Fishman EK, Kuhajda FP, Meziane MM, Khouri NF, Zerhouni EA, Siegelman SS: Solitary bronchioloalveolar carcinoma: CT criteria. Radiology 1988, 167:379-382.

42. Li M, Ito H, Wada H, Tanaka F: Pit-fall sign on computed tomography predicts pleural involvement and poor prognosis in non-small cell lung cancer. Lung Cance 2004, 46:349-355.

43. Baylin SB, Ohm JE: Epigenetic gene silencing in cancer - a mechanism for early oncogenic pathway addiction? Nat Rev Cancer 2006, 6:107-116.

44. MacLeod AR, Rouleau J, Szyf M: Regulation of DNA methylation by the Ras signaling pathway. J Biol Chem 1995, 270:11327-11337.

45. Oelke K, Richardson B: Decreased T cell ERK pathway signaling may contribute to the development of lupus through effects on DNA methylation and gene expression. Int Rev Immunol 2004, 23:315-331.

46. Pruitt K, Ulkü AS, Frantz K, Rojas RJ, Muniz-Medina VM, Rangnekar VM, Der CJ, Shields JM: Ras-mediated loss of the pro-apoptotic response protein Par-4 is mediated by DNA hypermethylation through Rafindependent and Raf-dependent signaling cascades in epithelial cells. J Biol Chem 2005, 280:23363-23370.

47. Lu R, Wang $X$, Chen ZF, Sun DF, Tian XQ, Fang JY: Inhibition of the extracellular signal-regulated kinase/mitogen-activated protein kinase pathway decreases DNA methylation in colon cancer cells. J Biol Chem 2007, 282:12249-12259.

48. Weisenberger DJ, Siegmund KD, Campan M, Young J, Long TI, Faasse MA, Kang GH, Widschwendter M, Weener D, Buchanan D, et al: CpG island methylator phenotype underlies sporadic microsatellite instability and is tightly associated with BRAF mutation in colorectal cancer. Nat Genet 2006, 38:787-793.

49. Porra V, Ferraro-Peyret C, Durand C, Selmi-Ruby S, Giroud H, BergerDutrieux N, Decaussin M, Peix JL, Bournaud C, Orgiazzi J, et al: Silencing of the tumor suppressor gene SLC5A8 is associated with BRAF mutations in classical papillary thyroid carcinomas. J Clin Endocrinol Metab 2005, 90:3028-3035

\section{Pre-publication history}

The pre-publication history for this paper can be accessed here: http://www.biomedcentral.com/1471-2407/11/147/prepub

doi:10.1186/1471-2407-11-147

Cite this article as: Ji et al:: Highly frequent promoter methylation and PIK3CA amplification in non-small cell lung cancer (NSCLC). BMC Cancer 2011 11:147.

\section{Submit your next manuscript to BioMed Central and take full advantage of:}

- Convenient online submission

- Thorough peer review

- No space constraints or color figure charges

- Immediate publication on acceptance

- Inclusion in PubMed, CAS, Scopus and Google Scholar

- Research which is freely available for redistribution

Submit your manuscript at www.biomedcentral.com/submit 